\title{
Modelling the Impacts of Inter-City Connectivity on City Specialisation
}

\author{
David Pierce, University of Leeds, Leeds, UK \\ Simon Shepherd, University of Leeds, Leeds, UK \\ Daniel Johnson, University of Leeds, Leeds, UK
}

\begin{abstract}
There is a high level of interest in investing in inter-city connectivity schemes. The rationale for these schemes is improved economic performance through increased productivity, jobs, and output. The mobility costs of switching between sectors for labour and capital may limit the level of sectoral specialisation achieved and the associated positive productivity impacts through localisation effects. To investigate these impacts, a stylised stock and flow model of two cities has been developed. The model has two business service sectors and a 20-minute reduction in rail travel times is introduced to understand the dynamics and the extent of barriers to localisation benefits due to labour and capital mobility costs, and to understand the degree to which these can be unlocked through intercity transport. The results show that mobility costs limit the potential for increased specialisation through investment in inter-city transport and that further specialisation is more likely to arise when the scheme effects differ between sectors and between cities.
\end{abstract}

\section{KEYWORDS}

Agglomeration, Inter-City Transportation, Localisation, Productivity, Specialisation, Urbanisation, Wider Economic Impacts

\section{INTRODUCTION}

There is a high level of interest in investing in inter-city connectivity schemes. The rationale for these schemes is improved economic performance through increased output and jobs and also through increased productivity which is currently a key focus of policymakers in the UK (HM Treasury (2015)) and several other countries including Japan (Government of Japan (2018)) and Australia (Australian Government Department of Finance (2017)). Current economic appraisal guidelines focus on direct cost savings and over the last 10 to 15 years methods have been developed to evaluate urbanisation effects within city regions but there has been much less focus on the effects of linking urban areas (Rosewell and Venables (2013)). In addition to urbanisation effects there may be significant localisation effects as a result of inter-city transport schemes if they can promote increased trade and specialisation (Venables (2017)).

\section{DOI: 10.4018/IJSDA.2019100106}

This article published as an Open Access article distributed under the terms of the Creative Commons Attribution License (http://creativecommons.org/licenses/by/4.0/) which permits unrestricted use, distribution, and production in any medium, provided the author of the original work and original publication source are properly credited. 
There is no complete method currently available for assessing inter-city connectivity benefits. Many of the modelling tools available focus on city regions rather than links between places. Many of the impacts are likely to take place over long timeframes which are currently modelled coarsely in many models and some of the more detailed modelling methods which take account of the microfoundations of trade and specialisation such as Spatial Computable General Equilibrium (SCGE) models are based on static rather than dynamic frameworks. Many inter-city transport schemes require significant capital investment and without dependable methods to assess their impact it raises policy questions about whether it is beneficial to invest in improving links between places.

For inter-city transport to induce increased specialisation the gains to labour and capital must outweigh any costs associated with switching sector. Sources of costs for inter-sectoral labour mobility include the time and monetary costs of searching for a new job (Fuller et al. (2014)). Other costs for labour of changing sector include the potential loss of human capital accumulated in the previous sector (Lee and Wolpin (2006)) and there may also be psychological costs of switching sector (DixCarneiro (2014)). Capital is also not perfectly mobile between sectors as there are costs involved in transferring it between sectors (Mussa (1978)). The presence of these costs of switching sector may limit the potential for gains from specialisation as a result of a transport scheme.

This paper contributes by investigating the impacts of inter-city transport on city specialisation using a stylised stock and flow model of two cities and two service sectors. The sectors are based on business services which are known to be particularly disposed to agglomeration effects (Graham (2006)) and a reduction in the rail travel time between the cities is introduced to test the impacts. The objectives of this paper are to:

1. Evaluate the extent to which barriers to localisation impacts due to factor mobility costs can be unlocked through inter-city transport;

2. Estimate the length of time adjustment to a new steady state; and

3. Estimate the relative size of urbanisation and localisation benefits.

The paper is organised as follows. Section 2 presents the literature review and the methodology is outlined in Section 3 including the structure of the model and the data inputs. In Section 4 the results are outlined for model simulations under different assumptions and this is followed by the conclusion.

\section{LITERATURE REVIEW}

There are two ways to look at the issue of how inter-city connectivity can impact on city specialisation: modelling and empirical.

\subsection{Modelling}

There have been several attempts to model agglomeration processes within clusters using the system dynamics approach. These studies show how the interdependence of variables can lead to efficiency gains for firms within a geographical area which over time can lead to the development of a competitive advantage. Many of these studies including Buendia (2005) and Dangelico et al. (2010) have focussed on the importance of knowledge spill overs rather than pecuniary externalities and the role of transportation has not been central to the analysis. In a more recent exception to this Diaz et al. (2016) modelled the interactions of transport infrastructure, population and GDP but inter-city connectivity was not considered. Other studies that have examined similar problems include Baporikar (2016) and Byambasuren et al. (2015) who assessed the impact of transport on economic development and Battini et al. (2013) who explored the effects of improving logistics in the healthcare market.

The system dynamics approach has also been used to model linkages between transport and the economy in models such as ASTRA (Assessment of Transport Strategies). In ASTRA transport 
costs affect trade which impacts on economic performance and there is a sector interchange model based on input-output linkages (Fermi et al. (2014)). In the model the input-output tables iterate over time but localisation effects are not included. The Urban Dynamic Model (UDM) (Swanson (2008)) is another model based on the system dynamics approach, but this is focused on city regions rather than inter-city transport. In addition, its assumptions on the dynamics including perfect matching between employers' needs and labour quality with a time lag have been critiqued for being unrealistic (MVA/ITS (2013)).

LUTI (Land-Use and Transport Interaction) and SCGE (Spatial Computable General Equilibrium) models are other model types commonly used to evaluate the economic impacts of transport infrastructure schemes (Oosterhaven and Knapp (2003)). LUTI models do not estimate wider economic impacts (WEI) directly but they can be calculated using the model outputs (MVA/ITS (2013)). For instance, Simmonds \& Feldman (2013) used the outputs from the DELTA model to estimate the WEI of transport schemes in the UK including agglomeration benefits based on the UK DfT's WebTAG guidelines. Drawbacks of using LUTI models include their assumptions that markets clear with prices equal to marginal cost and also that markets are perfectly competitive (Vickerman and Ulied (2012)). Another shortcoming of LUTI models is that they are based on determining equilibria at points in time rather than modelling continuous dynamic processes (Swanson (2008)).

SCGE models are based on micro-foundations and some models are specifically designed to enable the estimation of indirect effects (Van Wee and Tavasszy (2008)) including agglomeration. The drawbacks of SCGE models are that they are predominantly static and most dynamic versions are recursive bringing together equilibriums forecast at different points in time (Bröcker and Korzhenevych (2013)). SCGE models have also been developed in continuous time based on perfect foresight but this assumption is unrealistic (Bröcker and Korzhenevych (2013)).

\subsection{Empirical}

Agglomeration benefits are based on a finding from the empirical literature that there is a positive relationship between city size and productivity. The evidence suggests that doubling economic mass leads to a 3 to 8 per cent increase in productivity (Rosenthal and Strange (2004)). The sources of agglomeration benefits were first identified by Marshall (1890) (Duranton and Puga (2004)) and are labour market matching, linkages between suppliers subject to increasing returns to scale in production and knowledge spill overs. There is an important distinction between agglomeration benefits deriving from urbanisation and localisation economies. The former stem from the productivity benefits of firms being located near to all other firms whereas the latter relate to the benefits of locating in close proximity to firms within the same sector. Localisation economies are particularly relevant to inter-city schemes as they may lead to increased trade flows allowing places to specialise in tasks in which they have a comparative advantage (Venables (2017)). This suggests that over shorter distances urbanisation benefits will dominate but over longer distances between cities localisation benefits due to specialisation may play an increasingly important role.

Urbanisation and localisation elasticities are typically estimated in the region of 0.01 to 0.10 (Broersma and Oosterhaven (2009)) but estimates can vary significantly by sector (Jofre-Monseny et al. (2011)). Graham (2009) estimated greater values for service sectors than in manufacturing industries. Within the service sector Graham (2009) estimated high values for business service sectors with estimated average urbanisation elasticities for Financial \& Insurance and Business \& Management Consultancy Services of 0.26 and 0.22 respectively and for the same sectors significant localisation elasticities of 0.06 and 0.12 respectively within $5 \mathrm{~km}$. Graham (2006) showed that urbanisation effects may also be subject to diminishing returns in many industries but not in business service sectors such as real estate, retail and business and financial services. The understanding of the relative sizes of urbanisation and localisation impacts remains a key gap in the literature.

The empirical evidence suggests that the benefits from agglomeration decay quickly over distance (Melo et al. (2016)) which is pertinent for the assessment of inter-city transport schemes 
where distances between cities can be large. Rice et al. (2006) estimated that urbanisation benefits drop rapidly beyond a 40-minute driving time. Graham (2009) estimated that localisation economies also decay with distance and found that only food and beverage manufacturing, computer and related activities and architecture and engineering activities exhibit elasticities which are significant at $25 \mathrm{~km}$. This evidence suggests that there may be a tipping point related to the travel time between places related to the size and sector splits of cities over which localisation benefits will not be significant.

There are costs for labour and capital of moving sector which may potentially limit the level of specialisation and the associated productivity benefits through increased localisation effects. The evidence suggests that the labour mobility cost of switching sector is lower for unskilled workers (Larch and Lechthaler (2011)) as many skilled occupations require specific skills and training. This implies that there will be a limit to the degree of specialisation which is possible if there are significant differences in the skills required in different sectors. There are also mobility costs for capital of moving sector such as time and resource costs (Morshed \& Turnovsky (2004)). Grossman (1983) highlights Neary (1978) and Mussa (1978) who suggest there may be a loss of efficiency initially if capital is moved between sectors but this diminishes over time. This suggests that there is a cost of moving capital between sectors in the short-run but in the long-run capital is perfectly mobile (Grossman (1983)). The extent of the mobility costs for labour and capital may limit the potential for specialisation changes due to inter-city transport through raising the productivity impact required to induce labour and capital to switch sectors.

Research examining the dynamics of inter-sectoral migration in response to changes in trade costs has been relatively limited (Dix-Carneiro (2014)). This is due to the use of static frameworks in which labour is either perfectly immobile or instantaneously mobile at zero cost (Artuc et al. (2010)). One of the few studies examining the transitional dynamics by Dix-Carneiro (2014) explored the impacts on the labour market in Brazil of trade liberalisation. It was found that 95 per cent of labour market effects took place within 9 years with no physical capital mobility but up to 30 years with imperfect physical capital mobility. The authors put forward two explanations for this. Firstly, the model includes human capital which is partly based on workers' experience in a sector which accumulates over time and means human capital takes longer to reach a new equilibrium across sectors. Secondly, the capital moving sectors leads to marginal positive changes in its productivity over time which allows more specialisation to take place.

The estimated adjustment times to a trade shock in the literature vary depending on the situation analysed and the assumptions made. Using a dynamic trade model Artuc et al. (2010) estimated that the removal of a 30\% tariff on manufacturing products led to a reallocation of labour between sectors based on wage differentials and 95\% of the impacts took place within 8 years. Ashournia (2015) used data from Denmark to find that $95 \%$ of labour reallocation between sectors took place over a period of just over 10 years following a trade liberalisation shock. Artuc and McLaren (2015) found switching costs between sectors can be significant and using a dynamic model estimated that sectoral redistribution of jobs due to a reduction in trade costs can take longer than 10 years. In a more global context Pessoa (2016) estimated that a 25\% reduction in trade costs between China and the rest of the world led to a $90 \%$ real income adjustment within 25 years.

\section{METHODOLOGY}

\subsection{Model Structure}

The analysis is based on an abstract dynamic model of two cities and two business service sectors. The cities are connected by inter-city rail and road links and each city has a core and periphery with intra-urban transport links. The structure of the model is shown in Figure 1.

The stock and flow model has been developed from theories from the literature which are well developed in this field. A diagram of the model structure is shown in Figure 2. 


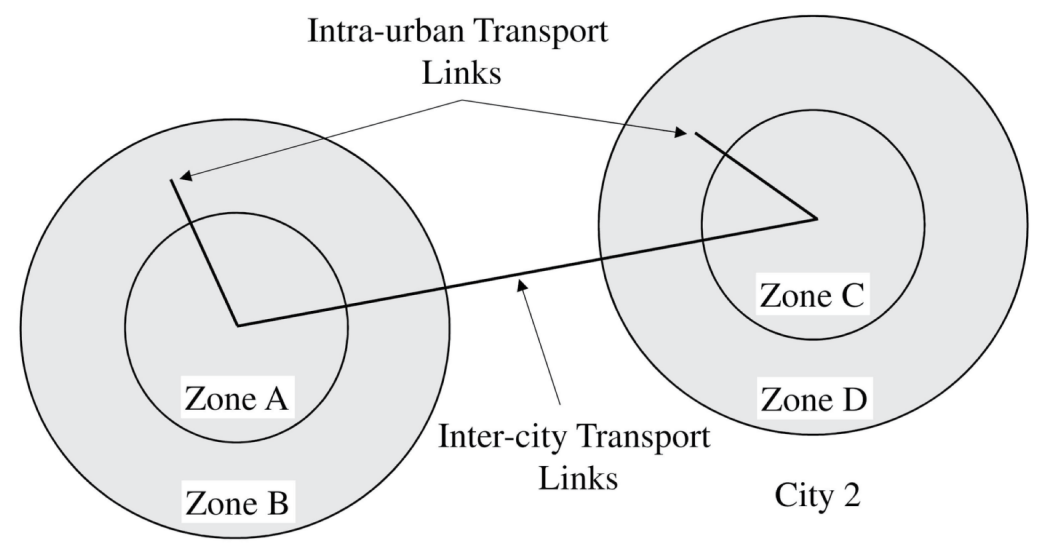

City 1

Figure 2. Stock and flow model diagram

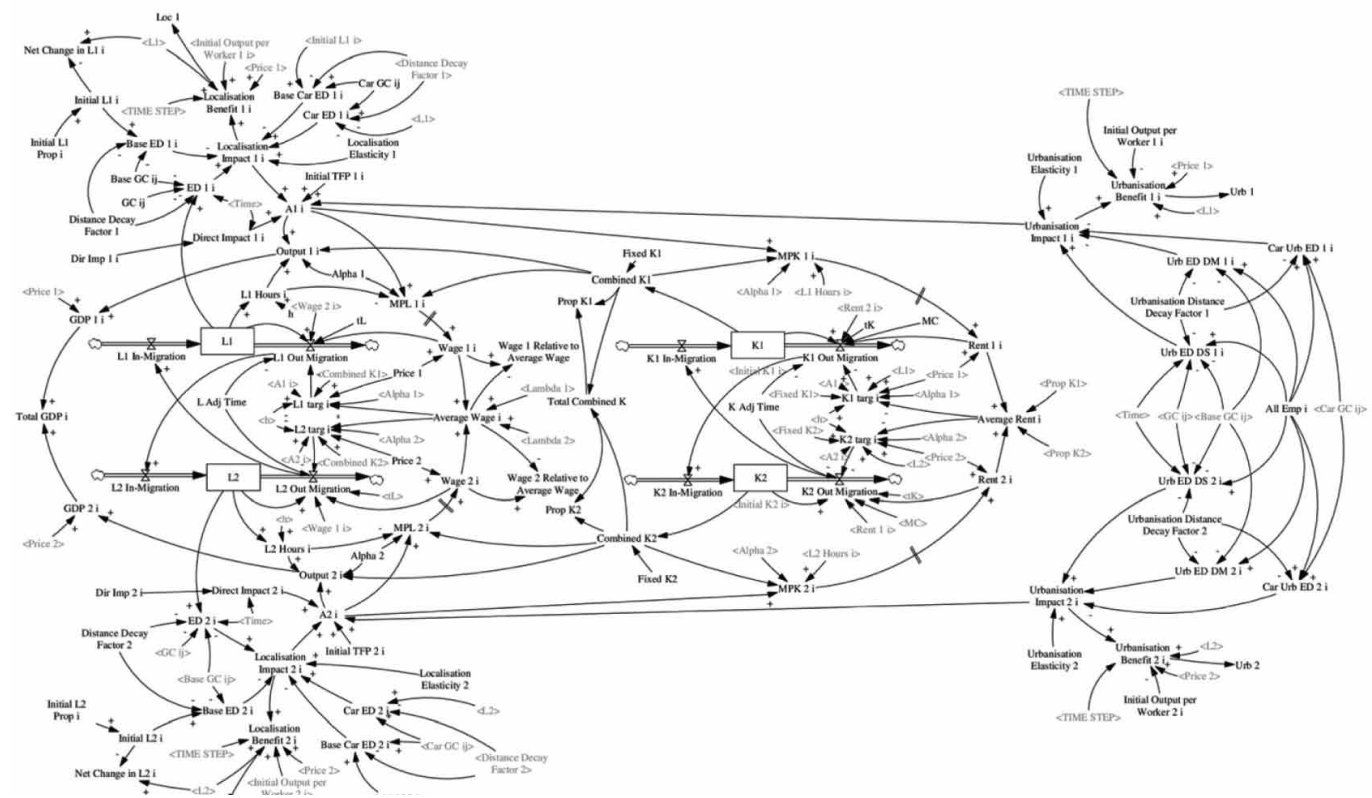

The stock of labour and capital in each sector in each zone is determined by its initial value and by inward and outward migration from and to the alternative sector within the zone. The total number of workers and amount of capital in each zone are fixed and each can move between sectors within a zone in response to differences in wages and rents respectively.

The main feedback loops in the model for the labour market are shown in Figure 3. In reinforcing feedback loop R1 an increase in the number of workers in a sector in a zone increases the effective density in that sector which increases the productivity of the workers through localisation impacts. This feeds through into a higher Total Factor Productivity (TFP) in the sector which increases the implied steady state labour and increases the incentive for more workers to move into that sector. 


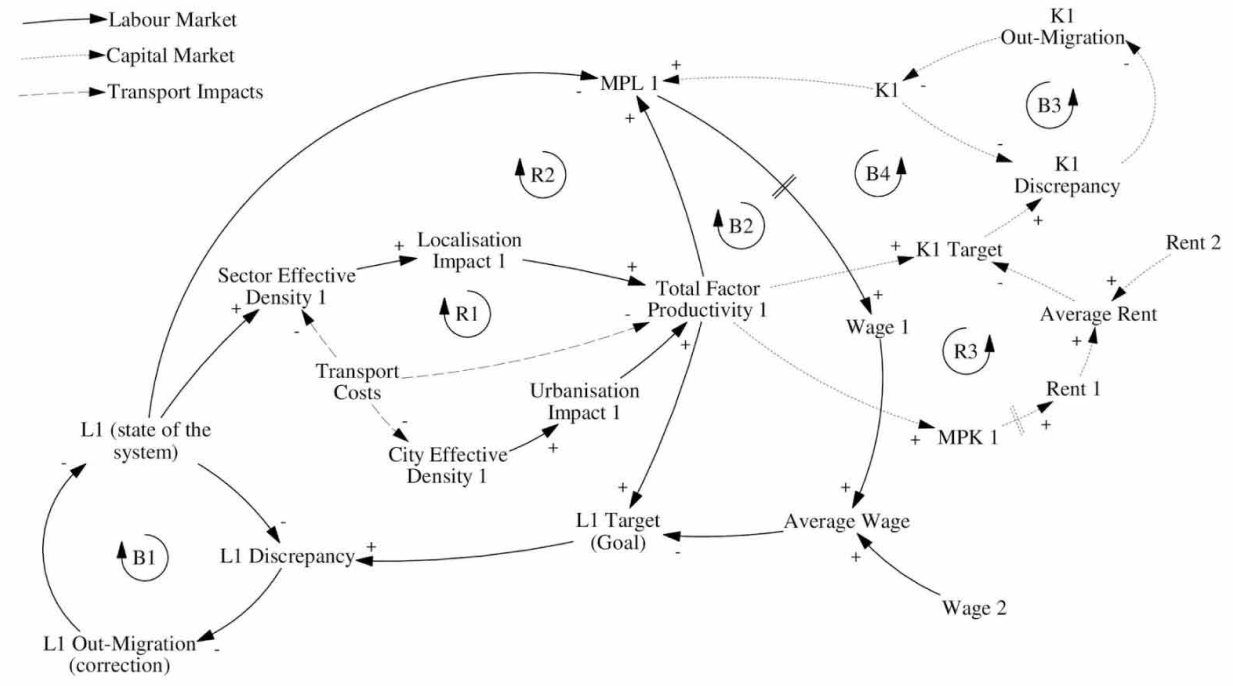

There is another reinforcing feedback loop in the labour market (R2) through which an increase in the number of workers in a sector lowers the marginal product of labour (MPL). This leads to a lower average wage which raises the target level of labour in the sector in the zone.

There are also two balancing feedback loops in the labour market. The goal-seeking archetype is used to move the current number of workers in the sector towards the target number in feedback loop B1. In feedback loop B2 an increase in the number of workers generates localisation impacts which feed through into increasing the average wage which reduces the implied steady state level of labour.

Labour can also impact on the capital market through two feedback loops. Firstly, there is reinforcing feedback loop R3 in which an increase in labour in a sector leads to localisation impacts which feed through into an increase in TFP. This leads to a higher marginal product of capital (MPK) which increases the average rent which lowers the implied steady state level of capital through the goal-seeking archetype loop for capital (B3). This feeds through into a lower MPL and average wage which raises the implied steady state level of labour. Secondly, there is a balancing feedback loop (B4) through which a rise in the number of workers increases TFP which leads to a higher implied steady state level of capital and then MPL leading to a lower implied steady state level of labour.

The main feedback loops in the capital market are shown in Figure 4. In addition to the feedback loops discussed previously there is a reinforcing feedback loop R4 through which an increase in capital in a sector in a zone leads to a lower MPK and then average rent which increases the implied steady state level of capital. In contrast to the labour stocks, the capital stocks do not feed directly into the effective densities for localisation impacts as these are a function of the number of workers in each zone and travel costs. This means that the reinforcing feedback loop for labour in which an increase in the number of workers in a sector increases TFP leading to further in-migration is not present for capital.

\subsection{Labour Market}

The labour $(L)$ stock in each sector $(1,2)$ and zone in the model is determined by its initial value and migration from and to the other sector within the same zone. The labour stocks for Sector 1 and 2 respectively in zone $i$ at time $t$ are given by the following equations: 


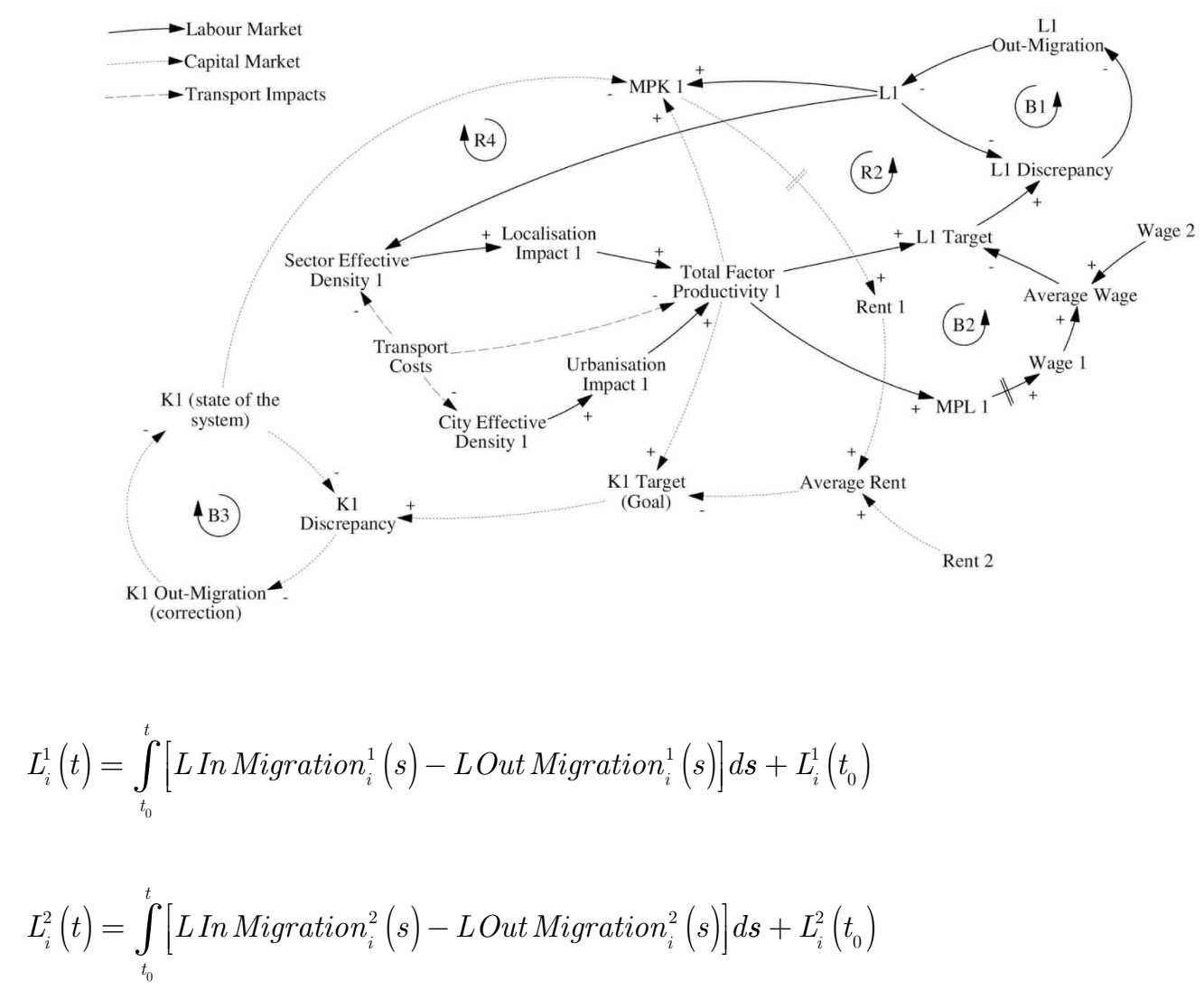

For ease of presentation time subscripts are omitted in the equations outlined below which are auxiliary variables where the calculation involves quantities in the same time step. A table of notation with all terms used in the model is provided in Appendix A.

A goal-seeking structure is used to determine the pathway to the final equilibrium level of labour in a sector within a zone as described in Sterman (2000). Labour can only move in one direction at each time step and the number of workers who migrate from a sector is determined by the following formulae for the two sectors:

$$
\begin{aligned}
& \left(\frac{L_{i}^{1}-\left(L^{*}\right)_{i}^{1}}{T A d j L}\right) \text { if } w_{i}^{2}-w_{i}^{1}>c L \\
& \left(\frac{L_{i}^{2}-\left(L^{*}\right)_{i}^{2}}{T A d j L}\right) \text { if } w_{i}^{1}-w_{i}^{2}>c L
\end{aligned}
$$

where $T A d j L$ is adjustment time for labour, $w$ is the nominal wage rate per hour, $c L$ is the sectoral mobility cost for labour and $\left(L^{*}\right)_{i}^{n}$ is the implied steady state value of labour in 
sector $n$ and zone $i$ implied by the average wage ( $\bar{w})$ across the two sectors within a zone. A higher adjustment time leads to a slower speed of adjustment and a value of 1.5 years was used to achieve adjustment to $98 \%$ of the initial gap in 6.5 years with fixed capital. This was based on defining a slightly quicker speed of adjustment compared to Dix-Carneiro (2014) who estimated $95 \%$ adjustment within 9 years but with the additional functionality of accumulated experience in a sector affecting productivity over time which slowed down the transition to a new steady state.

The number of units of output (Y) produced by firms in each sector in each zone is determined using a Cobb-Douglas production function for each sector $n$ :

$$
Y_{i}^{n}=A_{i}^{n}\left(h L_{i}^{n}\right)^{1-\alpha_{i}^{n}}\left(K_{i}^{n}\right)^{\alpha_{i}^{n}}
$$

where $A$ is Total Factor Productivity (TFP), $h$ is the average annual number of hours worked by workers each year, $K$ is capital (£) and $\alpha$ is the income share of capital. The nominal wage rate per hour for workers is given by:

$$
w_{i}^{n}=M P L_{i}^{n} P^{n}
$$

where $P$ is price $(\mathfrak{E})$ per unit which is set to 1 in both sectors and $M P L$ is the marginal product of labour which is determined by:

$$
M P L_{i}^{n}=\left(1-\alpha_{i}^{n}\right) A_{i}^{n}\left(K_{i}^{n} / h L_{i}^{n}\right)^{\alpha_{i}^{n}}
$$

It is assumed that productivity changes do not feed through into changes in wages immediately. This is modelled through introducing a delay between a change in the marginal product of labour in a sector and the wage rate. This is applied using a third order exponential delay with a time delay of six months based on the assumption that workers have annual pay reviews and so, on average, productivity changes are reflected in wage rates six months later.

The implied steady state value of labour is determined by setting the wage from Equations (6) and (7) equal to the average wage and rearranging to express in terms of $L$ which gives:

$$
\left(L^{*}\right)_{i}^{n}=1 /\left(\left(\bar{w}_{i} /\left(1-\alpha_{i}^{n}\right) P^{n} A_{i}^{n}\right)^{1 / \alpha_{i}^{n}}\left(h_{i}^{n} / K_{i}^{n}\right)\right)
$$

\subsection{Capital Market}

The capital $(K)$ stocks for sectors 1 and 2 respectively in each zone $i$ at time $t$ are given by:

$$
\begin{aligned}
& \left.K_{i}^{1}(t)=\int_{t_{0}}^{t}\left[K \text { In Migration }_{i}^{1}(s)-{\text { KOut } \text { Migration }_{i}^{1}}_{(s)}\right)\right] d s+K_{i}^{1}\left(t_{0}\right) \\
& K_{i}^{2}(t)=\int_{t_{0}}^{t}\left[K \text { In Migration }_{i}^{2}(s)-\text { KOut Migration }{ }_{i}^{2}(s)\right] d s+K_{i}^{2}\left(t_{0}\right)
\end{aligned}
$$


The migration of capital between sectors within a zone is based on the same structure as labour:

$$
\begin{gathered}
\left(\frac{K_{i}^{1}-\left(K^{*}\right)_{i}^{1}}{T A d j K}\right) \text { if } r_{i}^{2}-r_{i}^{1}>c K \\
\left(\frac{K_{i}^{2}-\left(K^{*}\right)_{i}^{2}}{T A d j K}\right) \text { if } r_{i}^{1}-r_{i}^{2}>c K
\end{gathered}
$$

where $\operatorname{Tadj} K$ is the adjustment time for capital, $\left(K^{*}\right)_{i}^{n}$ is the implied steady state value of capital in sector $n$ in zone $i, r$ is rent $(£)$ and $c K$ is the sectoral mobility cost for capital. As with the labour market the adjustment time for capital is set to 1.5 years. The nominal rent for capital is given by:

$$
r_{i}^{n}=M P K_{i}^{n} P^{n}
$$

where $M P K$ is the marginal product of capital This is calculated for each sector in each zone using the formula:

$$
M P K_{i}^{n}=\alpha_{i}^{n} A_{i}^{n}\left(K_{i}^{n}\right)^{\alpha_{i}^{n}-1}\left(h L_{i}^{n}\right)^{1-\alpha_{i}^{n}}
$$

There is a delay between changes in productivity which feed into the MPK and then rent. The delay between productivity changes and rents are modelled in the same way as labour with a third order exponential delay with a time delay of six months.

The implied steady state value of capital $\left(K_{i}^{n}\right)^{*}$ is determined across each sector and zone by equating the monetary value of MPK with the average rent $(\bar{r})$ and rearranging to express in terms of capital which gives:

$$
\left(K^{*}\right)_{i}^{n}=\left(\bar{r} /\left(h_{i}^{n} L_{i}^{n}\right)^{1-\alpha_{i}^{n}} \alpha_{i}^{n} P^{n} A_{i}^{n}\right)^{1 /\left(\alpha_{i}^{n}-1\right)}
$$

The specialisation of capital in one sector within a zone is specified as a minimum of $20 \%$. This is to reflect that in major cities it is usually found that there is a minimum proportion of the economy in each business service sector to serve the local market.

\subsection{Economic Benefits}

The business user benefits of the transport scheme and the localisation and urbanisation impacts are calculated using the methodology outlined in Appendix B. These are then used to estimate TFP which feeds into the calculation of the wage rate and capital rent through Equations (7) and (14) respectively: 


$$
A_{i}^{n}=\operatorname{Initial} A_{i}^{n}+D I R_{i}^{n}+\left(1+U R B_{i}^{n}\right)+\left(1+L O C_{i}^{n}\right)
$$

\subsection{Data Inputs}

The data inputs used in the model runs for the number of jobs, capital, TFP and GDP per worker for Sector 1 are shown in Table 1. The Sector 2 inputs are symmetrical to those for Sector 1 but with the higher number of workers and capital in Zones C and D (City 2) rather than in Zones A and B (City 1). This set up implies that Cities 1 and 2 have a comparative advantage in Sectors 1 and 2 respectively. With zero mobility costs the system goes to a maximum specialisation endpoint with the cities specialised in the sector in which they have the comparative advantage.

The sectors which have been selected for the analysis are business services such as finance, media and high-tech, in which firms are known to cluster together (Venables, Laird and Overman (2014)). The two sectors are presumed to require similar skills and workers are assumed to be able to move between sectors without further training. An income share for capital of 0.35 is used for both sectors.

The GDP per capita inputs are based on UK data (DfT (2013)) for Producer Services in the north of England. The TFP for each sector in each zone is estimated as a function of the existing level of localisation impacts. This is calculated by estimating the productivity change from 1,000 workers in each zone for the sector to the number of workers given in Table 1 applying the localisation elasticity. The capital in each sector and zone is then calculated as the level required to equate to the total GDP given the level of labour, TFP and the income share of capital. There is a consistent equilibrium with no movement of labour and capital between sectors before the transport scheme opens in Year 5.

The UK average number of hours worked per worker of 1,676 (OECD (2018)) is used to calculate the annual number of labour hours worked. An urbanisation elasticity of 0.03 and distance decay factor of 1.746 are used for both sectors, with the latter the value estimated for Producer Services in Graham et al. (2009). For localisation impacts an elasticity of 0.03 is used for both sectors and a distance decay factor of 2 to represent that these effects decay more rapidly over distance than urbanisation impacts.

The annual number of inter-city rail trips across the two sectors is assumed to be 1.9 million oneway trips based on ticket sales data. The Do-Minimum journey times for public transport (PT) and car are shown in Table 2. The PT journey times are based on an average in-vehicle travel time between the cities of 60 minutes and also include 5 minutes for access and egress time at each station, a 10 minute walk to the destination from the station and assume that passengers arrive 5 minutes before

\section{Table 1. Economic inputs for Sector 1}

\begin{tabular}{|c|c|c|c|c|c|}
\hline \multirow{2}{*}{ Economic Variable } & \multicolumn{2}{|c|}{ City 1} & \multicolumn{2}{|c|}{ City 2} & \multirow{2}{*}{ All Zones } \\
\hline & Zone A & Zone B & Zone C & Zone D & \\
\hline Number of Jobs & 60,000 & 24,00 & 40,000 & 16,000 & 140,000 \\
\hline Total Jobs & - & - & - & - & $1,000,000$ \\
\hline Capital Inputs (£m) & $£ 4,833$ & $£ 1,933$ & $£ 3,222$ & $£ 1,289$ & - \\
\hline TFP & 11.25 & 11.16 & 11.12 & 11.03 & - \\
\hline GDP per Worker $(\mathfrak{f})$ & $£ 73,107$ & $£ 72,539$ & $£ 72,257$ & $£ 71,718$ & - \\
\hline $\mathrm{GDP}(£ \mathrm{~m})$ & $£ 4,386$ & $£ 1,741$ & $£ 2,890$ & $£ 1,147$ & - \\
\hline Wage per hour (£) & $£ 28.35$ & $£ 28.13$ & $£ 28.02$ & $£ 27.81$ & - \\
\hline Annual Capital Rent (£) & $£ 0.318$ & $£ 0.315$ & $£ 0.314$ & $£ 0.312$ & - \\
\hline
\end{tabular}


Table 2. Do-minimum public transport and car journey times (minutes)

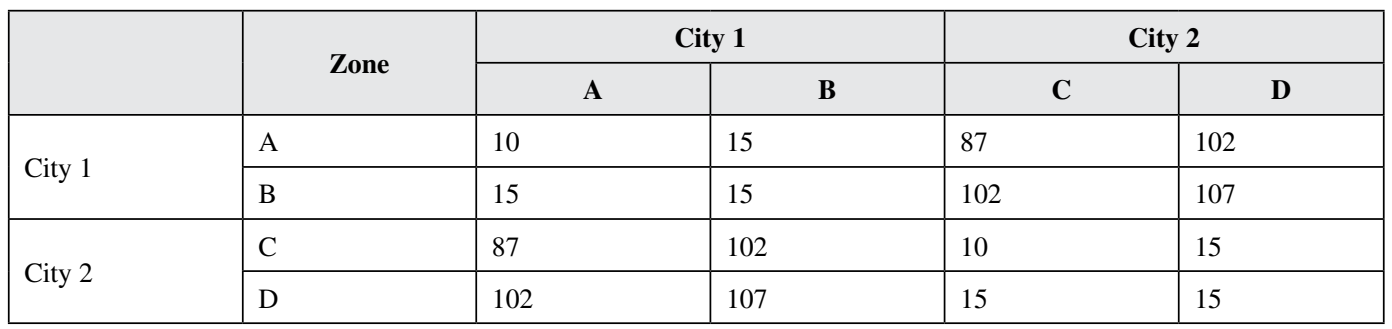

their departure. It is assumed that business trips between the core and periphery take 15 minutes and this trip time is also assumed for trips within the periphery zone of each city. It is assumed that car journey times between the zones are the same as PT.

\section{RESULTS}

The 20-minute journey time improvement on the inter-city rail link is introduced in Year 5. This was estimated to lead to a $19.5 \%$ increase in the number of rail trips and the average benefit per single passenger trip was estimated as $£ 1.68$. Total business user benefits were calculated as $£ 64.3 \mathrm{~m}$ over the 60-year appraisal period using a 2010 discount base year and discount rates from UK Department for Transport appraisal guidelines (DfT (2017)). The results by sector and zone are shown in Table 3 .

\subsection{Simulation With Equal Trip Rates per Job}

The model was run first under the assumption that the business user benefits of the transport scheme are split between sectors in a zone based on the same trip rate per job. This led to a productivity uplift of $0.19 \%$ applied to each sector in each zone. The mobility costs were set at $1 \%$ higher than the initial wage and rent differentials between sectors in the core zones giving a mobility cost of moving sector for labour of $£ 558$ per worker and for capital of 0.37 p per $£ 1$ of capital per year.

The model was simulated under these assumptions and it was found that the transport scheme did not generate any changes in specialisation. This is because although the transport scheme leads to productivity gains through user benefits, localisation and urbanisation effects it does not lead to a higher wage or rent differential than the labour and capital mobility costs respectively. The wage differential between Sector 1 and Sector 2 in City 1 for this model simulation is shown in Figure 5.

Figure 5 shows that the gap between the wage in Sector 1 and 2 decreases in both zones in City 1 after the transport scheme improvement in Year 5. These changes are driven by localisation impacts as the business user and urbanisation impacts lead to the same relative productivity impact for each

Table 3. Present value of business user benefits ( $£ \mathrm{~m}, 2021$ values and 2010 prices) over 60 years (excluding background economic growth)

\begin{tabular}{|l|l|l|l|l|}
\hline \multicolumn{1}{|c|}{ Zone } & \multicolumn{1}{c|}{ Sector 1 } & \multicolumn{1}{c|}{ Sector 2 } & \multicolumn{1}{c|}{ Total } \\
\hline \multirow{3}{*}{ City 1 } & A & 13.89 & 9.15 & 23.03 \\
\cline { 2 - 5 } & B & 5.50 & 3.62 & 9.12 \\
\hline \multirow{2}{*}{ City 2 } & C & 9.15 & 13.89 & 23.03 \\
\hline & D & 3.62 & 5.50 & 9.12 \\
\hline & Total & 32.15 & 32.15 & 64.31 \\
\hline
\end{tabular}


Figure 5. Wage 1 - Wage 2 (2021 Values \& 2010 Prices) in City 1 with equal trip rates per job

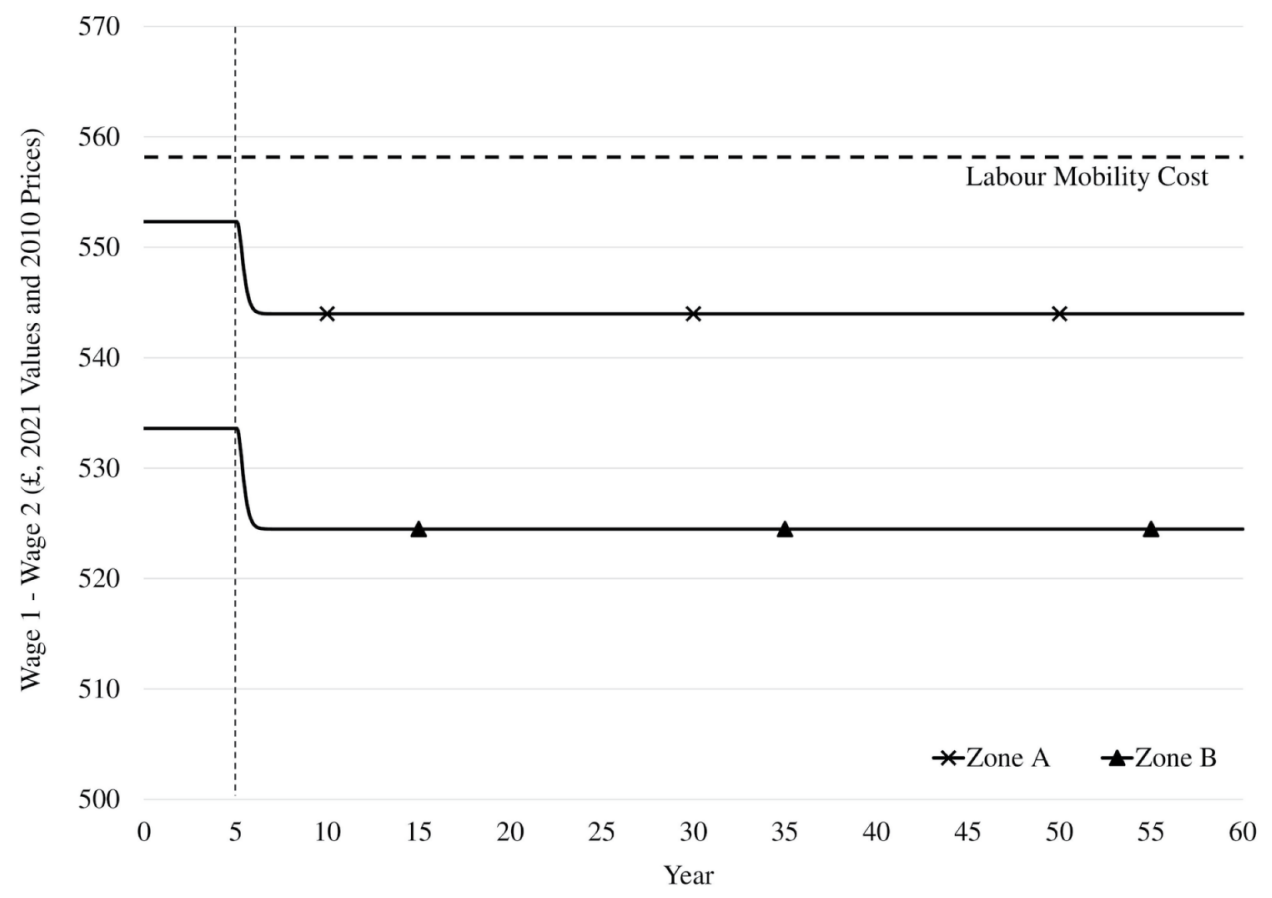

sector within each zone. The localisation effect is positive in both sectors but approximately twice as high for the less productive sector in each zone. This is because the sector with fewer workers in a zone gains a greater proportional increase in effective density as the workers are brought in closer proximity to zones with a higher number of workers in the same sector. This leads to a greater increase in the wage rate in the less productive sector in each zone which explains the slight narrowing of the wage differential between the more and less productive sectors.

The scale of the business user benefits were then increased to understand how significant the transport scheme would need to be to generate changes in specialisation. It was estimated that business user benefits would need to be multiplied by approximately 140 to generate a high enough increase in wages and rents in the more productive sector in each zone to move to a new steady state with maximum specialisation. Such high business user benefits are unrealistic which suggests that under the assumptions of the model distributing business user benefits based on an equal trip rate per job will result in no changes in specialisation due to an inter-city transport scheme.

\subsection{Simulation With Uneven Trip Rates per Job}

In reality the impacts on sectors in different locations are unlikely to be symmetric. In particular, it might be expected that more productive sectors in each location may benefit more from an intercity transport scheme as they may be able to use their productive advantage to increase their market share in the other city. This scenario was tested in the model through adjusting how the user benefits were split between sectors in each zone by assuming that workers in the more productive sector make twice as many trips per job as in the less productive sector. This meant that the productivity increase in the more productive sector $(0.232 \%)$ was twice the increase in the less productive sector $(0.116 \%)$ in each zone. 
Under these assumptions the impacts on the wage and rent differentials between sectors were again found not to be great enough to exceed the mobility costs of moving sector and the cities remained in their initial steady states. The model was then used again to calculate the size of business user benefits which would be required to move away from the initial steady state and it was estimated that they would need to be multiplied by 2.5 . This is significantly less than the level required when the user business benefits were based on equal trip rates as outlined above.

The wage differential between Sectors 1 and 2 and localisation impacts for City 1 with uneven trip rates and business user benefits multiplied by 2.5 are shown in Figures 6 and 7 respectively. Figure 6 shows that the transport scheme initially leads to an increase in the wage differential between sectors. This is due to the higher business user benefits in the more productive sector which outweigh the higher localisation effects in the less productive sector. These impacts lead to a higher increase in TFP in the more productive sector which increases the wage and rent differentials to just above the mobility costs and a small amount of labour and capital moves into the more productive sector. There are also links between changes in the labour and capital markets. An increase in capital in a sector increases the MPL in the sector which increases the attractiveness of the sector to workers. Similarly, as labour moves into the sector this increases TFP which increases the rent differential which leads to more capital moving into the sector. As labour and capital become concentrated in the more productive sector in each zone this leads to higher localisation impacts in the more productive sector (Figure 7) which accentuates the process of increased specialisation.

The delays on changes in the wage rates and rents lead to oscillation of the wage and capital differentials around the mobility costs between Years 8 and 14. This is because when the gap between the differential and the mobility cost is small only a limited amount of capital and labour moves sector in each time step. If the other factor remains constant there will be diminishing marginal returns which leads to a falling wage or rent differential which explains the fluctuations. To move beyond

Figure 6. Wage 1 - Wage 2 (2021 Values \& 2010 Prices) with uneven trip rates per job and BUB x2.5

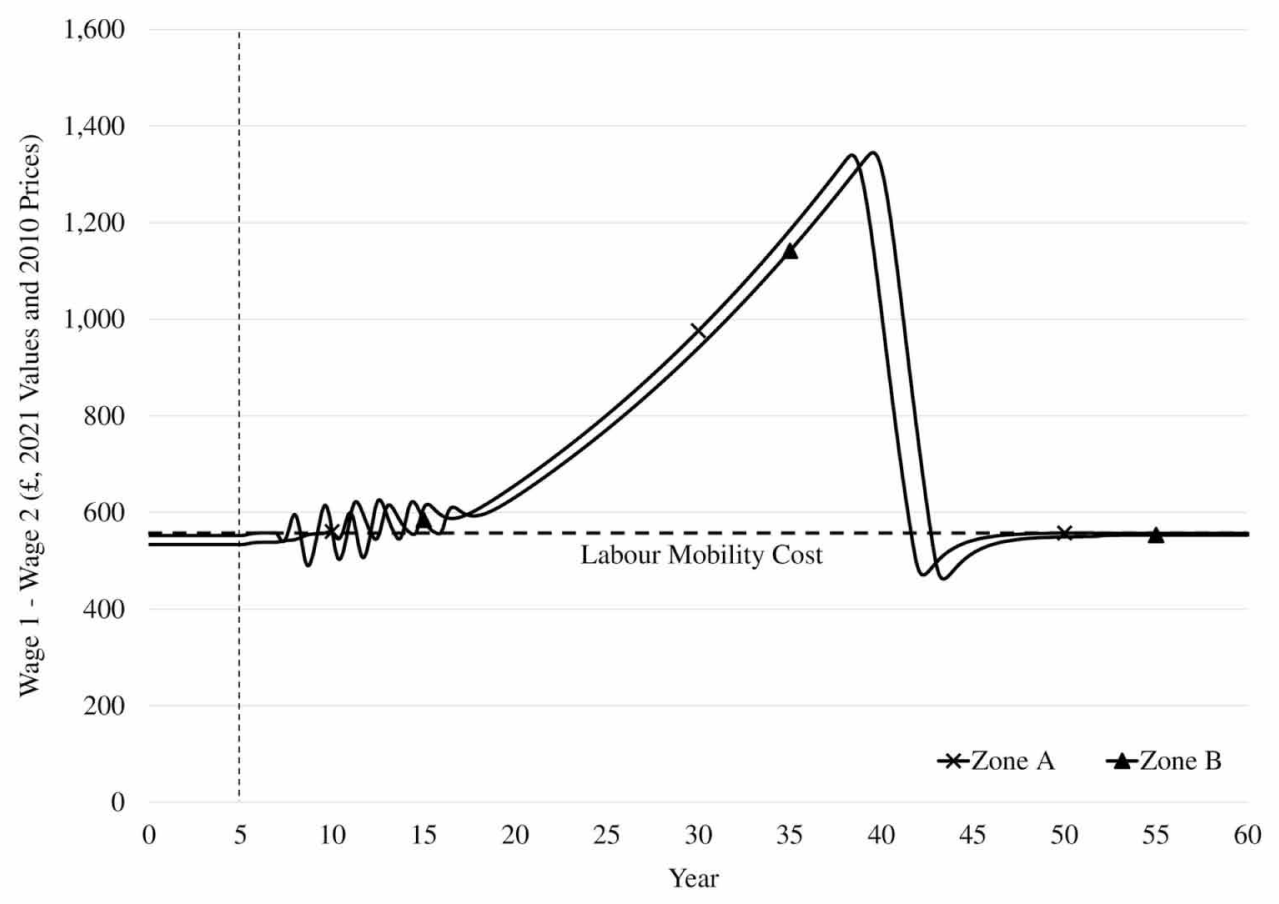


Figure 7. Localisation impacts in Sector 1 with uneven trip rates per job and BUB x2.5

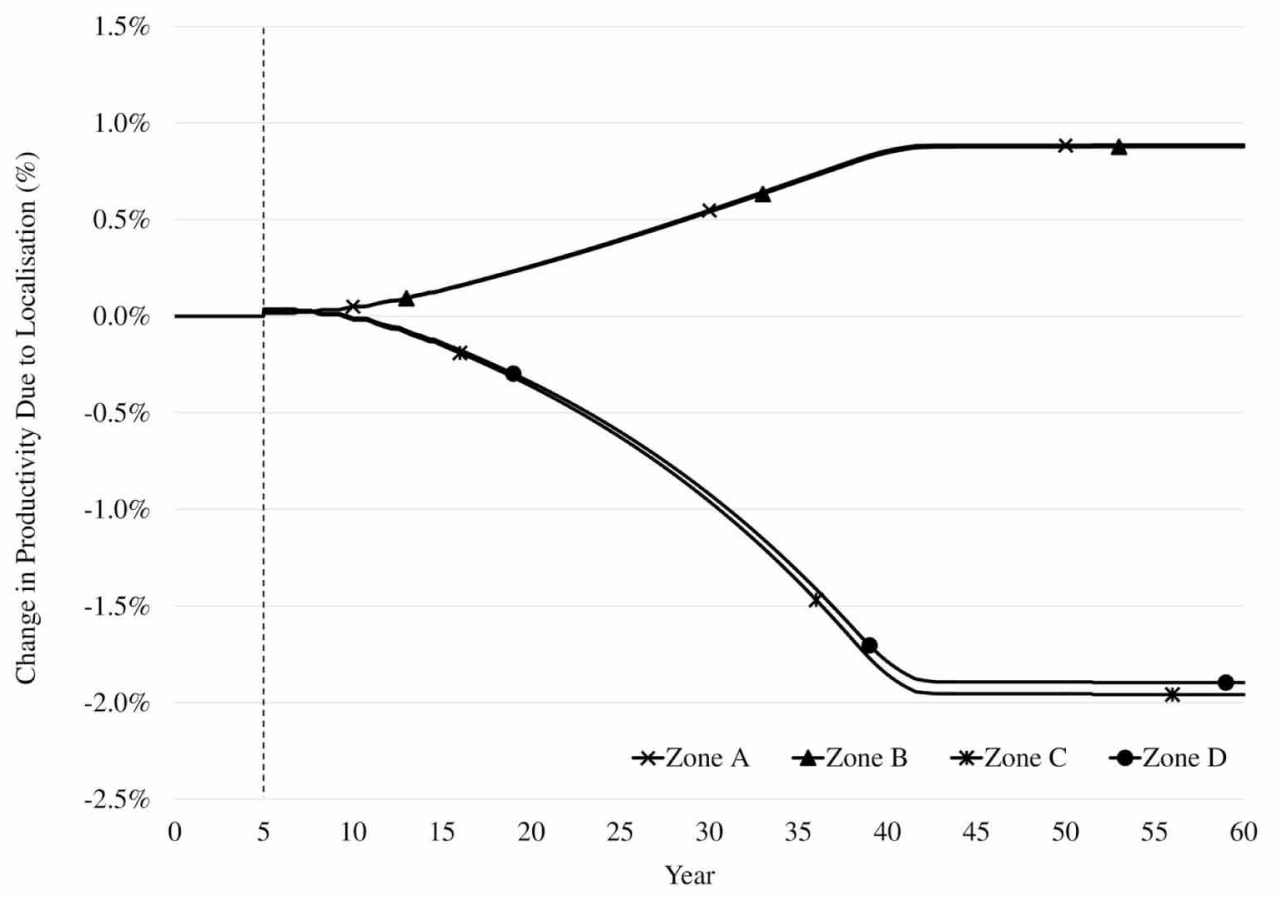

the tipping point both labour and capital need to switch sector in a reinforcing feedback loop and the gap between the differentials and mobility costs aren't high enough between Years 8 and 14 to sustain this. The back and forth between the capital and labour markets continues until the changes in localisation impacts lead to wage and rent differentials which are high enough to generate a sustained movement of both labour and capital into the more productive sector.

After Year 38 and 39 for Zone A and B respectively there is a sudden fall in the wage differential. This is because at this point the proportion of capital in the less productive sector reaches the minimum limit of $20 \%$ and no more capital migration occurs. At this point the wage differential is still higher than the labour mobility cost in the more productive sector and workers continue to move into it. Capital no longer migrates in response which means the MPL falls in the sector due to diminishing marginal returns to labour. Similarly, in Sector 2 the MPL and therefore the wage rate increase as workers leave the sector. This leads to a narrowing of the wage differential between the sectors until it is below the labour mobility cost and no further migration between the sectors takes place.

The transition to the new steady state endpoint for the number of workers is shown in Figure 8. The opening of the transport scheme leads to workers moving towards Sector 1 in Zones A and B (City 1) and Sector 2 in Zones C and D (City 2) which is in line with comparative advantage as expected. The number of workers adjusts to $95 \%$ of the initial gap in 34 years of the transport scheme opening. This speed of adjustment is slightly slower than Dix-Carneiro (2014) who estimated that $95 \%$ of labour market changes due to a trade liberalisation took place in 30 years.

It has been assumed up to this point that the relative mobility costs for labour and capital are similar. In reality, however, there may be differences in the costs incurred for each factor in moving sector. To test the impact of this simulations were undertaken with different levels of mobility costs for capital and labour to test their impact on the level of specialisation changes. Holding the mobility cost for labour constant it was estimated that if the capital mobility cost was increased to $0.43 \mathrm{p}$ per 
Figure 8. Number of workers in Sector 1 with uneven trip rates per job and BUB x2.5

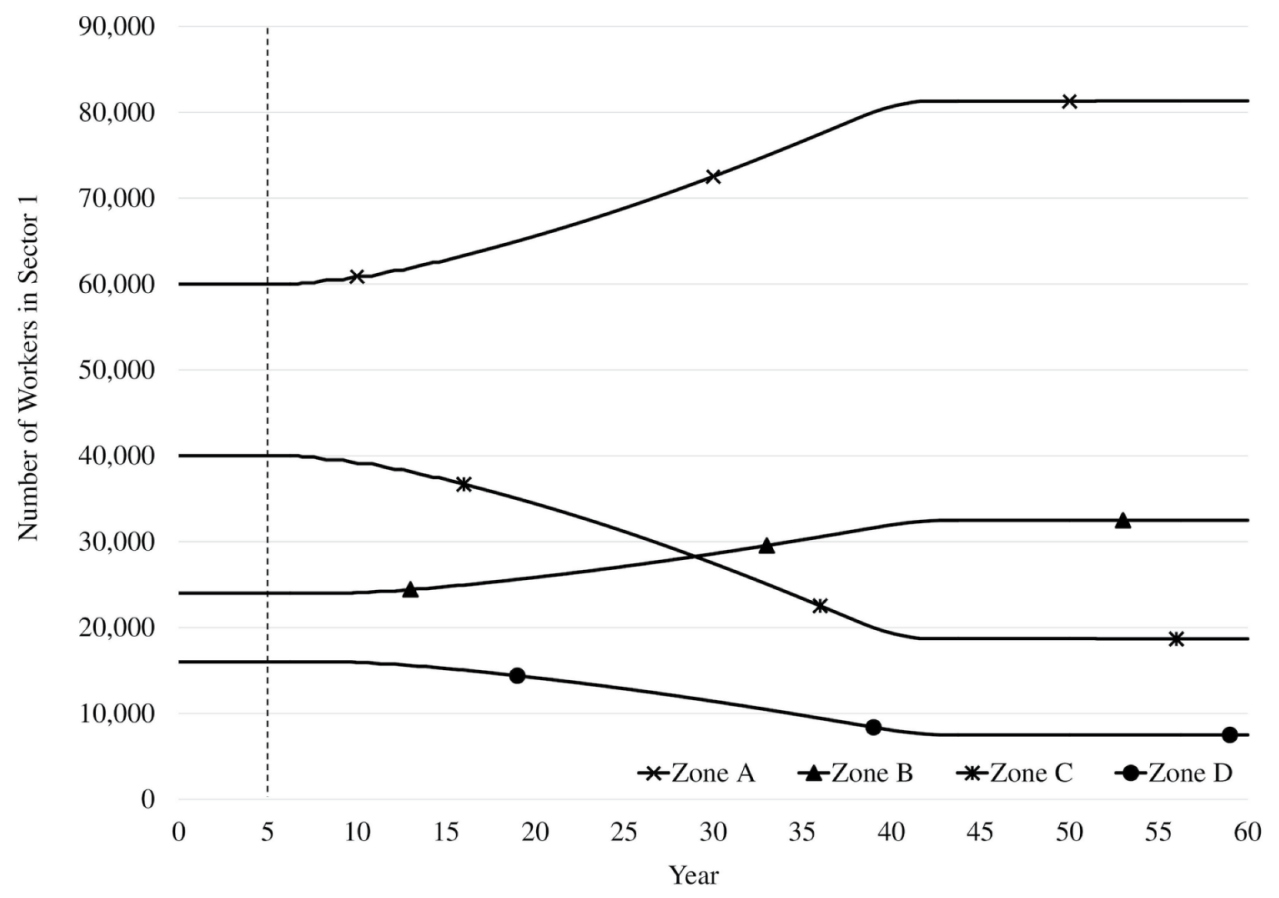

$£ 1$ of capital per year (17\% higher than the rent differential in the core zones) another type of steady state was possible where there is a limited change in specialisation. It is easier to show these effects with an even higher capital mobility cost and Figure 9 shows the wage differential over time in Sector 1 in City 1 with a mobility cost of 0.48 p per $£ 1$ of capital per year.

Figure 9 shows that following the opening of the transport scheme the business user benefits lead to an increase in the wage differential between Sector 1 and 2 to just above the labour mobility cost in Year 6. This leads to workers moving from Sector 2 to 1 in Zone A which increases TFP in Sector 1 due to localisation impacts but not enough to induce a movement of capital which remains fixed. As workers move into Sector 1 its wage rate falls due to diminishing marginal returns to labour and the wage rate in Sector 2 increases which leads to a reduction in the wage differential. The differential falls below its initial level due to the delay on wage rate changes which leads to an overshooting of the number of workers moving into Sector 1. It should be noted that there are no specialisation changes in the periphery (i.e. Zone B) as the change in the wage differential between the sectors isn't great enough to exceed the labour mobility cost.

Figure 10 show the localisation impacts which are impacting on these changes. The initial increase in effective density in Year 5 is greater for the less productive sector in each zone as there are fewer workers in these sectors and a greater increase in effective density is therefore realised. As workers move to the more productive sector this partially offsets this pattern of localisation effects which leads to a small increase in the wage differential at the end of Year 6 which can be seen visibly for Zone B in Figure 9. This effect is also occurring in Zone A but it is not great enough to reverse the direction of the wage differential in this zone which stabilises at $£ 516$ per worker at the new steady state.

The estimated steady state number of workers in Sector 1 in Zone A for this simulation is shown in Figure 11 along with the results for varying levels of business user benefits. This shows that there is no change in the requirement for business user benefits to be multiplied by 2.5 for the transport 
Figure 9. Wage 1 - Wage 2 (2021 Values \& 2010 Prices) with uneven trip rates per job, BUB $\times 2.5 \&$ K mobility cost of $0.48 p$ per $£ 1$ of capital

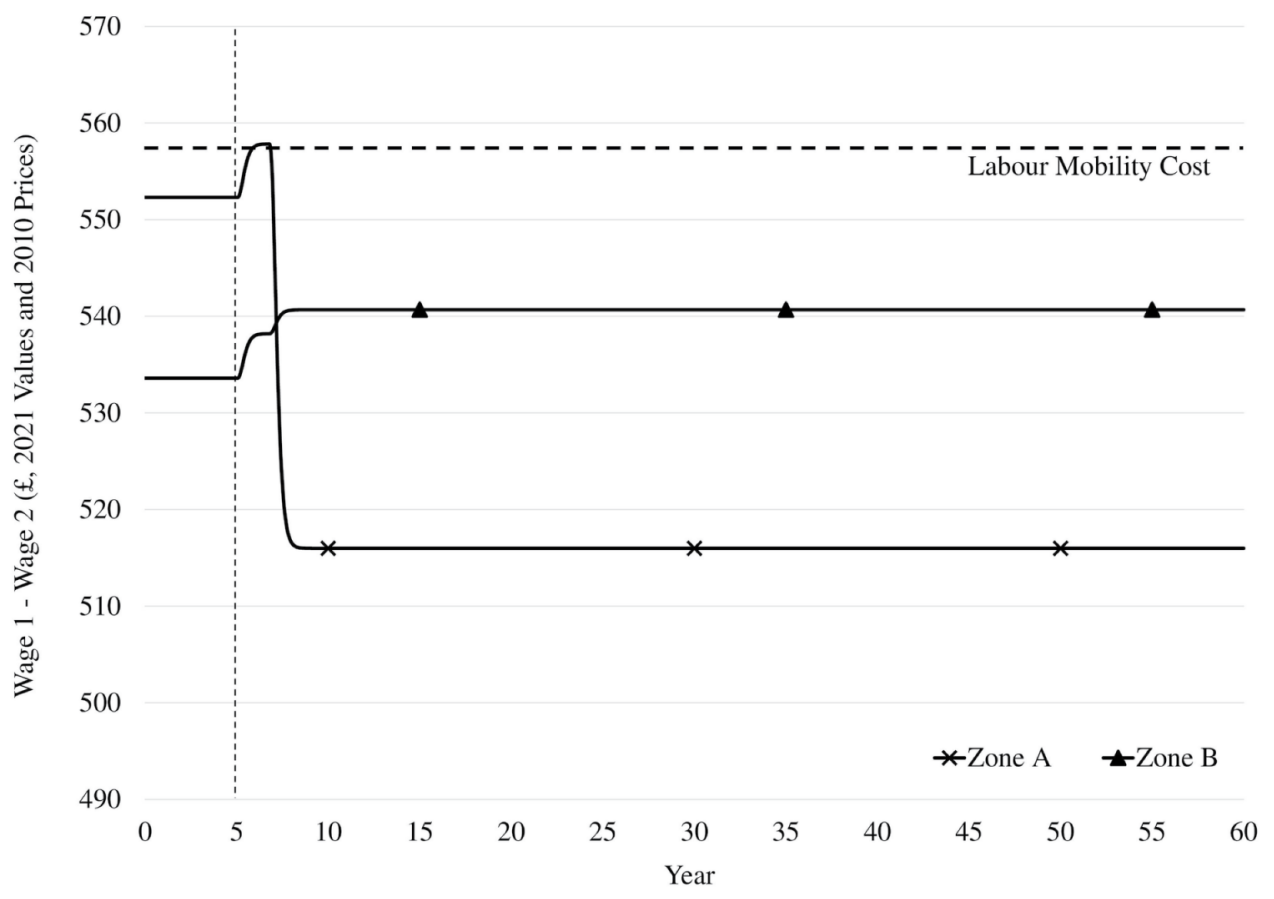

Figure 10. Localisation impacts (\%) in Sector 1 with uneven trip rates per job, BUB x2.5\& K mobility cost of $0.48 p$ per $£ 1$ of capital

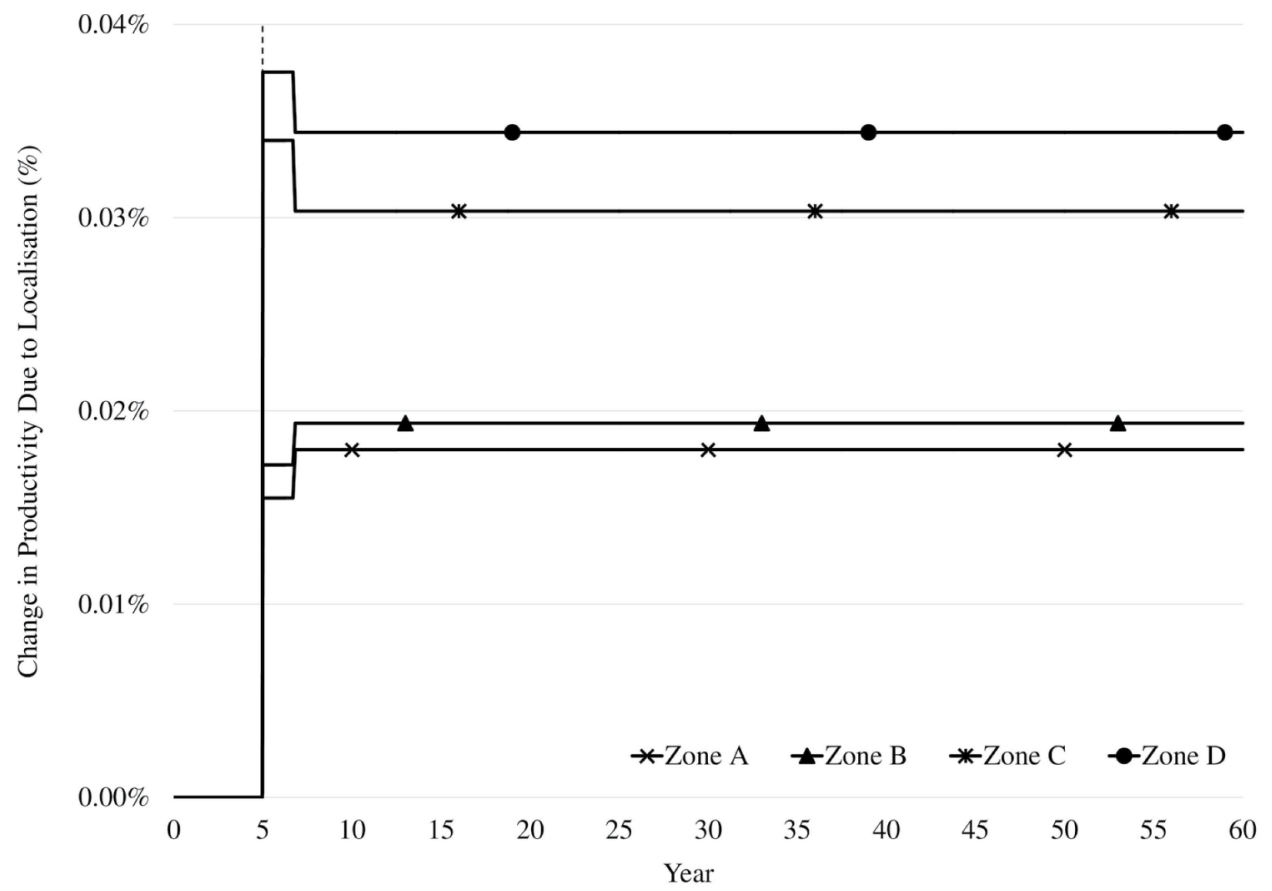


scheme to generate changes in specialisation but the requirement for maximum specialisation has increased to 3.4 times business user benefits.

The model was also run with a higher mobility cost for labour than capital but it was found that this could not generate a limited specialisation endpoint under the assumptions of the model.

The present value of economic benefits of the transport scheme for the three types of steady state with a higher mobility cost for capital from Figure 11 are shown in Table 4.

These results show that if the impacts of the transport scheme are high enough then it can induce changes in specialisation which can lead to significant localisation impacts. These benefits give an indication of the maximum level of the impact but in reality labour and capital won't necessarily always move sector to achieve a higher return and the realisation of all of these potential benefits may not be possible.

To achieve these changes in specialisation an inter-city rail scheme would need to be significant to generate large enough time savings and/or be implemented on a route which is used for a high number of business trips. This would suggest that specialisation changes are more likely to occur when synergies exist between sectors in different cities which could be expected to lead to higher trip rates. In addition, changes in specialisation could potentially be realised for longer distances between cities where the time savings may be more significant although the distance decay of urbanisation and localisation effects may limit the scope of the impacts and there may also be fewer business trips over longer distances.

\section{CONCLUSION}

In this paper a stylised dynamic model of two cities and two business service sectors has been developed to understand the magnitude of the impacts and transition to a new steady state resulting from a

Figure 11. Steady state number of workers in Sector 1 in Zone A with uneven trip rates per job and K mobility cost of $0.48 \mathrm{p}$ per $£ 1$ of capital

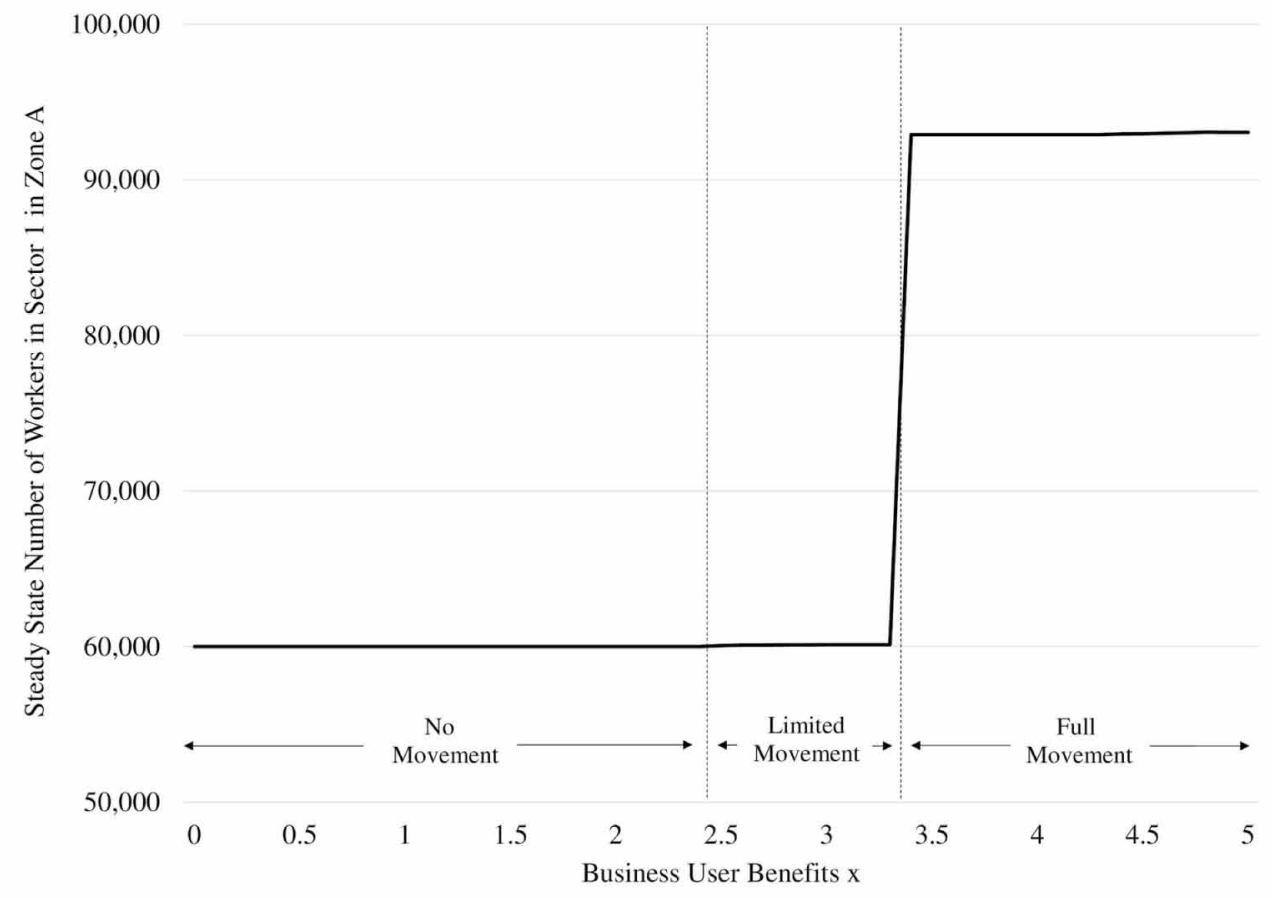


Table 4. Present value of benefits ( $£ \mathrm{~m}, 2021$ values and 2010 prices) with uneven trip rates per job and $\mathrm{K}$ mobility cost of $0.48 \mathrm{p}$ per $£ 1$ of capital (excluding background economic growth)

\begin{tabular}{|l|l|l|l|l|l|l|l|l|l|}
\hline \multirow{2}{*}{ Zone } & \multicolumn{3}{|c|}{ BUB x1 } & \multicolumn{3}{c|}{ BUB x2.5 } & \multicolumn{3}{c|}{ BUB x5 } \\
\cline { 2 - 10 } & \multicolumn{1}{|c|}{ BUB } & \multicolumn{1}{|c|}{ Urb } & \multicolumn{1}{c|}{ Loc } & \multicolumn{1}{c|}{ BUB } & \multicolumn{1}{c|}{ Urb } & \multicolumn{1}{c|}{ Loc } & \multicolumn{1}{c|}{ BUB } & Urb & Loc \\
\hline A (S1) & 17.3 & 22.9 & 11.5 & 43.3 & 22.9 & 13.2 & 86.6 & 26.3 & 364.7 \\
\hline B (S1) & 6.9 & 9.3 & 5.1 & 17.1 & 9.3 & 5.7 & 34.3 & 10.6 & 142.3 \\
\hline C (S1) & 5.7 & 15.1 & 16.6 & 14.3 & 15.1 & 14.9 & 28.5 & 11.7 & -203.8 \\
\hline D (S1) & 2.3 & 6.1 & 7.3 & 5.7 & 6.1 & 6.7 & 11.3 & 4.8 & -78.9 \\
\hline A (S2) & 5.7 & 15.1 & 16.6 & 14.3 & 15.1 & 14.9 & 28.5 & 11.7 & -203.8 \\
\hline B (S2) & 2.3 & 6.1 & 7.3 & 5.7 & 6.1 & 6.7 & 11.3 & 4.8 & -78.9 \\
\hline C (S2) & 17.3 & 22.9 & 11.5 & 43.3 & 22.9 & 13.2 & 86.6 & 26.3 & 364.7 \\
\hline D (S2) & 6.9 & 9.3 & 5.1 & 17.1 & 9.3 & 5.7 & 34.3 & 10.6 & 142.3 \\
\hline Total & 64.3 & 106.8 & 80.9 & 160.8 & 106.8 & 81.0 & 321.5 & 106.9 & 448.7 \\
\hline
\end{tabular}

20-minute inter-city rail journey time improvement. The results show that changes in specialisation don't happen easily with factor mobility costs but they are more likely to arise when the effects differ between sectors and between cities. When the business user benefits lead to the same increases in productivity in both sectors in a zone then the transport improvement required to induce further specialisation needs to be significant. Based on an assumption of 1.9 million 1-way trips between the cities and a reduction in rail journey time from 60 to 40 minutes it was forecast that an unrealistic level of business user benefits would be required to move the cities towards further specialisation.

When higher trip rates are assumed in the more productive sector in each location the scale of benefits required to change the level of specialisation is smaller but still significant. This suggests that investment in transport links between cities for which there is potential for significant time savings could generate changes in specialisation such as when there are synergies between sectors in different cities and therefore a high number of business trips. There may also be scope for investing in links between cities which are further away for which time savings may be greater but there may be fewer business trips using such links and there is also the distance decay of urbanisation and localisation effects to consider. In addition, specialisation changes may result from an inter-city transport improvement if the existing links are poor and transport is acting as a constraint on business trips.

The length of time of adjustment to a new steady state of maximised specialisation was estimated at 34 years. This is slightly longer than in other studies which have estimated sectoral adjustment times to changes in trade costs such as Dix-Carneiro (2014). The urbanisation benefits due to the transport scheme were estimated as greater than localisation benefits if the scheme does not generate further specialisation changes. If the scheme leads to maximised specialisation the potential localisation benefits are shown to be large and several times the level of urbanisation benefits.

Further research is needed to understand the impact on the end point and dynamics of the inclusion of other potentially important variables such as labour skills and vertical linkages between sectors. It would also be informative to estimate the impacts for cities with different characteristics and for different sectors and also to extend the analysis to evaluate the relative impacts of investing in inter- and intra-city connectivity schemes.

\section{ACKNOWLEDGMENT}

This research was supported by an iCASE studentship funded by the EPSRC and Arup (Grant Number EP/ N509243/1). I am also grateful to Dr James Laird for his constructive comments on an earlier draft of the paper. 


\section{REFERENCES}

Artuc, E., Chaudhuri, S., \& McLaren, J. (2010). Trade Shocks and Labor Adjustment: A Structural Empirical Approach. The American Economic Review, 100(3), 1008-1045. doi:10.1257/aer.100.3.1008

Artuc, E., \& McLaren, J. (2015). Trade Policy and Wage Inequality: A Structural Analysis with Occupational and Sectoral Mobility. Journal of International Economics, 97(2), 278-294. doi:10.1016/j.jinteco.2015.06.001

Ashournia, D. (2015). Labour Market Effects of International Trade when Mobility is Costly (Economics Working Paper Series 751). Department of Economics, University of Oxford.

Australian Government Department of Finance. (2017). Corporate Plan 2017-18, Covering Reporting Period 2017-18 to 2020-21. Australia: Department of Finance.

Baporikar, N. (2016). Infrastructure Development as a Catalyst for Social-Economic Advancement. International Journal of System Dynamics Applications, 5(4), 101-113. doi:10.4018/IJSDA.2016100106

Battini, D., Faccio, M., Persona, A., \& Sgarbossa, F. (2013). Modelling the Growing Process of Integrated Healthcare Supply Networks. International Journal of System Dynamics Applications, 2(1), 1-13. doi:10.4018/ ijsda.2013010101

Bröcker, J., \& Korzhenevych, A. (2013). Forward looking dynamics in spatial CGE modelling. Economic Modelling, 31, 389-400. doi:10.1016/j.econmod.2012.11.031

Broersma, L., \& Oosterhaven, J. (2009). Regional labor productivity in the Netherlands: Evidence of agglomeration and congestion effects. Journal of Regional Science, 49(3), 483-511. doi:10.1111/j.1467-9787.2008.00601.x

Buendia, F. (2005). Increasing Returns to Economic Activity Concentration. In International Conference of the System Dynamics Society, Boston, MA, July 17-21.

Byambasuren, T., Purevjav, A.-O., \& Erdenekhuyag, E. (2015). Economic Impacts of the Government Investment Policy: Dynamic CGE Model. International Journal of System Dynamics Applications, 4(1), 96-118. doi:10.4018/ IJSDA.2015010104

Dangelico, R. M., Garavelli, A. C., \& Petruzzelli, A. M. (2010). A system dynamics model to analyze technology districts' evolution in a knowledge-based perspective. Technovation, 30(2), 142-153. doi:10.1016/j. technovation.2009.09.006

Department for Transport (DfT) (2013). Wider Impacts Dataset.

Department for Transport (DfT) (2017). WebTAG Databook.

Diaz, R., Behr, J. G., \& Ng, M. W. (2016). Quantifying the economic and demographic impact of transportation infrastructure investments: A simulation study. Simulation, 92(4), 1-17. doi:10.1177/0037549716632343

Dix-Carneiro, R. (2014). Trade Liberalization and Labor Market Dynamics. Econometrica, 82(3), 825-885. doi:10.3982/ECTA10457

Duranton, G., \& Puga, D. (2004). Micro-foundations of urban agglomeration economies. In J.V. Henderson \& J.-F. Thisse (Eds.), Handbook of Regional and Urban Economics (pp. 2063-2117). Elsevier.

Fermi, F., Fiorello, D., Krail, M., \& Schade, W. (2014). Description of the ASTRA-EC model and of the user interface. Deliverable D4.2 of ASSIST. Project co-funded by European Commission $7^{\text {th }}$ RTD Programme. Karlsruhe, Germany: Fraunhofer-ISI.

Fuller, D., Lkhagvasuren, D., Terracol, A., \& Auray, S. (2014). A Dynamic Analysis of Sectoral Mobility, Worker Mismatch, and the Wage-Tenure Profile. 2014 Meeting Papers 876. Society for Economic Dynamics.

Government of Japan. (2018). Abenomics. Tokyo: Cabinet Office.

Graham, D. J. (2006). Wider economic benefits of transport improvements: link between agglomeration and productivity: Stage 2 Report. Imperial College London.

Graham, D. J. (2009). Identifying urbanisation and localisation externalities in manufacturing and service industries. Papers in Regional Science, 88(1), 63-84. doi:10.1111/j.1435-5957.2008.00166.x 
Graham, D. J., Gibbons, S., \& Martin, R. (2009). Transport Investment and the Distance Decay of Agglomeration Benefits. Imperial College London.

Grossman, G. M. (1983). Partially Mobile Capital: A general approach to two-sector trade theory. Journal of International Economics, 15(1-2), 1-17. doi:10.1016/0022-1996(83)90038-7

Jofre-Monseny, J., Marín-López, R., \& Viladecans-Marsal, E. (2011). The mechanisms of agglomeration: Evidence from the effect of inter-industry relations on the location of new firms. Journal of Urban Economics, 70(2), 61-74. doi:10.1016/j.jue.2011.05.002

Larch, M., \& Lechthaler, W. (2011). Comparative Advantage and Skill-Specific Unemployment. The B.E. Journal of Economic Analysis \& Policy, 11(1), 1-58. doi:10.2202/1935-1682.2673

Lee, D., \& Wolpin, K. I. (2006). Intersectoral Labor Mobility and the Growth of the Service Sector. Econometrica, 74(1), 1-46. doi:10.1111/j.1468-0262.2006.00648.x

Marshall, A. (1890). Principles of Economics. London: Macmillan.

Melo, P. C., Graham, D. J., Levinson, D., \& Aarabi, S. (2016). Agglomeration, Accessibility and Productivity: Evidence for large metropolitan areas in the US. Urban Studies (Edinburgh, Scotland), 54(1), 1-17.

Morshed, M., \& Turnovsky, S. J. (2004). Sectoral adjustment costs and real exchange rate dynamics in a two-sector dependent economy. Journal of International Economics, 63(1), 147-177. doi:10.1016/S0022-1996(03)00038-2

Mussa, M. (1978). Dynamic Adjustment in the Heckscher-Ohlin-Samuelson Model. Journal of Political Economy, 86(5), 775-791. doi:10.1086/260711

MVA/ITS. (2013). Assessment of Methods for Modelling and Appraisal of the Sub-National, Regional and Local Economy Impacts of Transport. Report for the Department for Transport.

Neary, J. P. (1978). Short-run capital specificity and the pure theory of international trade. Economic Journal (London), 88(351), 488-510. doi:10.2307/2232049

OECD. (2018). OECD Statistics: Labour Force Statistics. Paris: OECD.

Oosterhaven, J., \& Knapp, T. (2003). Spatial Economic Impacts of Transport Infrastructure Investments. In A. Pearman, P. Mackie, \& J. Nellthorp (Eds.), Transport Projects, Programmes and Policies: Evaluation Needs and Capabilities (pp. 87-105). London: Ashgate Publishing.

Pessoa, J. P. (2016). International Competition and Labor market Adjustment (Discussion Paper 1411). Centre of Economic Performance, London, UK.

Rice, P., Venables, A. J., \& Pattachini, E. (2006). Spatial determinants of productivity: Analysis for the regions of Great Britain. Regional Science and Urban Economics, 36(6), 727-752. doi:10.1016/j.regsciurbeco.2006.03.006

Rosenthal, S. S., \& Strange, W. C. (2004). Evidence on the Nature and Sources of Agglomeration Elasticities. In J.V. Henderson \& J.-F. Thisse (Eds.), Handbook of Regional and Urban Economics (pp2119-2171). Elsevier .

Rosewell, B., \& Venables, A.J. (2013). High Speed Rail, Transport Investment and Economic Impact. London: HS2 Ltd.

Simmonds, D. C., \& Feldman, O. (2013). Modelling the Economic Impacts of Transport Changes: Experience and Issues. In F. Pagliara, M. de Bok, D. Simmonds, \& A. Wilson (Eds.), Employment location in cities and regions: models and applications (pp. 33-56). Springer-Verlag. doi:10.1007/978-3-642-31779-8_3

Sterman, J. (2000). Business Dynamics: Systems Thinking and Modeling for a Complex World. Boston, MA: Irwin/McGraw-Hill.

Swanson, J. (2008). Transport and the Urban Economy: The Urban Dynamic Model. In Proceedings from REAL CORP 008. Vienna, Austria.

H.M. Treasury. (2015). Fixing the foundations: Creating a more prosperous nation. 
Van Wee, B., \& Tavasszy, L. A. (2008). Ex-Ante Evaluation of mega-projects: methodological issues and cost-benefit-analysis. In H. Priemus, B. Flyvbjerg, \& B. van Wee (Eds.), Decision-making on Megaprojects: Cost-benefit Analysis, Planning and Innovation (pp. 40-65). Cheltenham, UK: Edwin Elgar. doi:10.4337/9781848440173.00009

Venables, A. J. (2017). Expanding cities and connecting cities: The wider benefits of better communications. Journal of Transport Economics and Policy, 51(1), 1-19.

Venables, A. J., Laird, J. J., \& Overman, H. G. (2014). Transport investment and economic performance: Implications for project appraisal (Research Report). Department for Transport, UK.

Vickerman, R., \& Ulied, A. (2012). Indirect and Wider Economic Impacts of High Speed Rail. In G. De Rus (Ed.), Economic Analysis of High-Speed Rail in Europe (pp. 89-118). Fundacion BBVA. 


\section{APPENDIX A: TABLE OF NOTATION}

\section{Table 5. Table of notation}

\begin{tabular}{|c|c|}
\hline Symbol & Description \\
\hline $\mathrm{L}$ & Labour Stock (Number of Workers) \\
\hline $\mathrm{K}$ & Capital Stock $(\mathfrak{f})$ \\
\hline $\mathrm{h}$ & Average Annual Number of Hours Worked per Worker \\
\hline A & Total Factor Productivity (TFP) \\
\hline$\alpha$ & Income Share of Capital \\
\hline $\mathrm{Y}$ & Number of Units of Output \\
\hline $\mathrm{i}$ & Zone \\
\hline $\mathrm{j}$ & Destination Zone \\
\hline $\mathrm{z}$ & All Zones \\
\hline $\mathrm{n}, \mathrm{S} 1, \mathrm{~S} 2$ & Sector, Sector 1 , Sector 2 \\
\hline$\lambda$ & Proportion of Number of Workers in Sector in Zone \\
\hline$\mu$ & Proportion of Capital in Sector in Zone \\
\hline w & Nominal Wage $(\mathfrak{f})$ per Hour \\
\hline $\mathrm{r}$ & Nominal Rent (£) \\
\hline MPL & Marginal Product (number of units of output) of Labour \\
\hline MPK & Marginal Product (number of units of output) of Capital \\
\hline $\mathrm{P}$ & Price $(£)$ per Unit \\
\hline TAdjL & Time of Adjustment for Labour \\
\hline TAdjK & Time of Adjustment for Capital \\
\hline $\mathrm{cL}, \mathrm{cK}$ & Sectoral Mobility Cost for Labour, Capital \\
\hline BUB & Business User Benefits ( $($ ) \\
\hline DIR & Direct Uplift to TFP due to Business User Benefits \\
\hline EDU & Effective Density for Urbanisation Impacts \\
\hline EDL & Effective Density for Localisation Impacts \\
\hline $\mathrm{E}$ & Employment (number of jobs) \\
\hline $\mathrm{GC}_{\mathrm{ij}}$ & Generalised Costs $(\mathfrak{f})$ from zone $\mathrm{i}$ to zone $\mathrm{j}$ \\
\hline $\mathrm{m}$ & Mode \\
\hline$\beta u$ & Distance Decay Factor for Urbanisation Impacts \\
\hline$\beta l$ & Distance Decay Factor for Localisation Impacts \\
\hline URB & Change in Productivity (\%) Due to Urbanisation Impacts \\
\hline LOC & Change in Productivity (\%) Due to Localisation Impacts \\
\hline $\mathrm{pu}$ & Urbanisation Elasticity \\
\hline $\mathrm{pl}$ & Localisation Elasticity \\
\hline WBU & Wider Economic Benefits ( $£$ ) due to Urbanisation \\
\hline WBL & Wider Economic Benefits $(£)$ due to Localisation \\
\hline GDPW $^{\mathrm{DM}}$ & GDP $(£)$ per Worker in the Do-Minimum \\
\hline TB & Total Economic Benefits (£) \\
\hline
\end{tabular}




\section{APPENDIX B: CALCULATION OF ECONOMIC BENEFITS}

The business user benefits are calculated using the standard rule-of-a-half formula using a rail business user value of time of $£ 32.76$ per hour (2021 Values, 2010 Prices). A rail demand elasticity of -0.8 is used to estimate the change in the number of trips. The business user benefits (BUB) are used to calculate the direct impact (DIR) uplift to TFP using the following formula for zone $i$ for e.g. Sector 1:

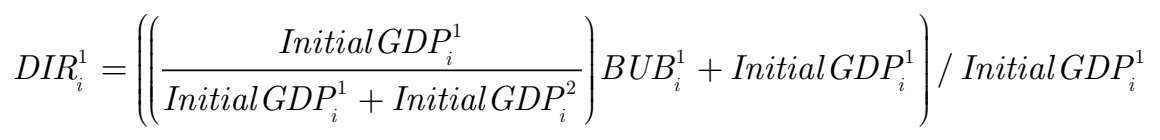

This impact is calculated for the scheme opening year and the uplift is then applied in all subsequent years. The urbanisation and localisation effective densities, $E D U$ and $E D L$ respectively, are calculated in a zone $i$ as a function of employment $(E)$ in all zones $(\mathrm{z})$ including zone $\mathrm{i}$ and the generalised cost (GC) of a trip between zone $\mathrm{i}$ and all zones are defined by:

$$
\begin{aligned}
& E D U_{i}^{n}=\sum_{z} \frac{E_{z}}{\left(G C_{i z}^{m}\right)^{\beta u^{n}}} \\
& E D L_{i}^{n}=\sum_{z} \frac{E_{z}^{n}}{\left(G C_{i z}^{m}\right)^{\beta l^{n}}}
\end{aligned}
$$

where $\beta u$ and $\beta l$ are the distance decay factors for urbanisation and localisation by sector respectively and $m$ is mode. The effective density is calculated separately for public transport and car which are then summed to give a total effective density. The productivity impacts are calculated separately at each time step for urbanisation $(U R B)$ and localisation $(L O C)$ based on the effective density in the Do-Minimum (DM) and Do-Something (DS) cases using the following formulae:

$$
\begin{aligned}
& U R B_{i}^{n}=\left[\left(\frac{E D U_{i}^{D S, n}}{E D U_{i}^{D M, n}}\right)^{p u^{n}}-1\right] \\
& L O C_{i}^{n}=\left[\left(\frac{E D L_{i}^{D S, n}}{E D L_{i}^{D M, n}}\right)^{p l^{n}}-1\right]
\end{aligned}
$$

where $p u$ and $p l$ are the elasticities for urbanisation and localisation respectively. The wider benefits for urbanisation $(W B U)$ and localisation $(W B L)$ are calculated using the formulae:

$$
\begin{aligned}
& W B U_{i}^{n}=U R B_{i}^{n} G D P W_{i}^{D M, n} E_{i}^{D S, n} \\
& W B L_{i}^{n}=L O C_{i}^{n} G D P W_{i}^{D M, n} E_{i}^{D S, n}
\end{aligned}
$$


where GDPW is the GDP per worker at Year Zero. Total benefits $(T B)$ at each time step are given by:

$$
T B_{i}^{n}=B U B_{i}^{n}+W B U_{i}^{n}+W B L_{i}^{n}
$$

David Elliott Pierce is a PhD student in Transport Studies at the University of Leeds. His research interests include Cost Benefit Analysis, Wider Economic Impacts and System Dynamics.

Simon P. Shepherd has worked at the Institute for Transport Studies since 1989. He gained his doctorate in 1994 applying state-space methods to the problem of traffic responsive signal control in over-saturated conditions. His expertise lies in modelling and policy optimisation ranging from detailed simulation models through assignment to strategic land use transport models. Recently he has focussed on optimisation of road user charging schemes and is currently working on aspects of competition between cities. He has applied system dynamics approaches to the transport sector, looking at toll competition between private operators; take up of electric vehicles and strategic modelling where he has been involved in the development of MARS a land use transport interaction model for the last ten years. The most recent application of which was for the Greater Jakarta Transport Authority to aid their master planning process (2017).

Daniel Johnson has worked at UNIVLEEDS since 2001. He is a transport economist with specific interests in passenger and freight transport modelling and appraisal. Key themes developed through his research at ITS include factors influencing trip making behaviour; valuations of journey attributes; assessment of the impacts of rail competition and scarcity; the link between public transport and the wider economy and society. 